\title{
Der «Kulturueli»
}

Erhard Taverna

* Dr. med. Ulrich Ammann, Schlossstrasse 1 A, 3800 Interlaken, Tel. 0338232123.
Ulrich Ammann*, von Brienzern oft «Kulturueli» benannt, hat in diesem Jahr in geistiger Frische seinen 80. Geburtstag gefeiert. Nach dem Medizinstudium in Bern und den üblichen Lehr- und Wanderjahren als Assistenzarzt eröffnete er in Brienz eine Praxis für Allgemeinmedizin, die er 1995 einem jungen Kollegen übergab. Neben seiner praktischen Tätigkeit und seinen Familienpflichten nahm er sich sehr viel Zeit für die zahlreichen Nebenberufe als Schriftsteller, Koautor, Musiker, Komponist, Chorleiter, Konzertkritiker, aktives Mitglied des Bezirksärztevereins, Tourismusförderer und Verwaltungsrat des historischen Grandhotels Giessbach. Wir sind es gewohnt, dass viele Ärzte früherer Jahrhunderte als Universalgelehrte sich einen Namen schufen. Die lange Aufzählung der Ammann'schen Tätigkeiten erinnert daran, dass es bis in die Gegenwart Ärztinnen und Ärzte gibt, die uns dieses Ideal vorleben.

Die wichtigste aller Liebhabereien blieb stets die Musik. Er leitete in seinen Jugendjahren drei Jazzbandformationen, denen er die Arrangements schrieb. Später begleitete er auf der Klarinette klassische und romantische Kompositionen, begann, «seriöse» Musik zu schreiben, und vertiefte sich autodidaktisch in die Kompositionslehre. Beim Durchblättern des dicken Werkverzeichnisses zeigt sich ein grosses Spektrum von Liedern zu jedem denkbaren Anlass, gesungen an Sängertagen und Musikfestwochen, in Kirchen und auf Dorfbühnen, in Frauen-, Männer- und gemischten Chören, die er oft noch selbst leitete. Zum breiten Repertoire von Ulrich Ammann gehören auch weltliche und geistliche Kantaten, vertonte Texte von Heine und Hesse, Albert Streich, Kurt Biener, David Künzler und vielen anderen. Ebenso vielfältig ist seine Kammermusik der Serenaden, Capriccios, Sonatinen, Märsche, Sonaten und Romanzen. Mit diesem Pensum, das ohne weiteres für einen eigenständigen Beruf ausgereicht hätte, war es aber nicht genug. Ein weiteres Werkverzeichnis listet die geschriebenen Bücher auf, von denen der Autor mit der Weisheit des Melancholikers vermerkt, dass ein Teil der Titel entweder vergriffen, vom Verlag vernichtet oder ihm wieder angeboten worden sei. Auch hier erstaunt die Bandbreite der Themen: ein Reisebericht aus Korsika, eine Bergdorfidylle mit kriminalistischem Hintergrund, Mozart auf der Reise nach Brienz, Kriminalgeschichten, Mär-

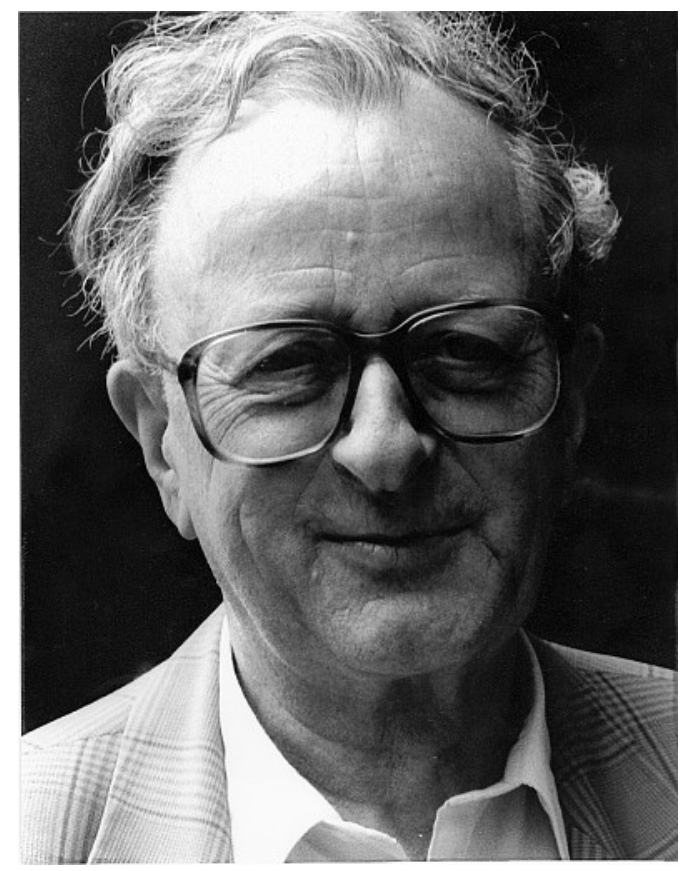

Photo: Peter Friedli, Arzt und Fotograf in Bern.

chen, Mundartspiele, Balladen und Aufsätze. Sachbücher zu Denkmälern, Bauten und Brunnen der Region sind erst wenige Jahre alt und durchaus noch zu beziehen.

Ein Kulturminister muss in allen möglichen Kommissionen mitarbeiten, Kinos, Bibliotheken und Schulen planen und als Brienzer natürlich auch die Schnitzlerschule fördern. Das Freilichtmuseum Ballenberg ist auch nicht weit entfernt, und da gibt es noch die Brienz-Rothorn-Bahn, Tennisplätze, Musikfestwochen in Interlaken und die Freunde der Dampfschifffahrt. So ein Leben lässt sich eigentlich nicht in Einzelheiten zerlegen, das ergäbe nur eine ermüdende und dennoch unvollständige Aufzählung, ohne den Generalisten im Kern zu erfassen. Ulrich Ammann ist eine Art bernisches Urgestein, ein Gesamtkunstwerk mit Landpraxis und diversen Aussenfilialen. Er hat stets aus dem Vollen geschöpft und reichlich zurückgegeben. Unzählige Patienten, Sänger, Leser, Zuhörer, Zuschauer und nicht zuletzt auch die kulturell interessierten Touristen werden es ihm verdanken. «Sic transit ...» hat er in einem Brief an die Redaktion geschrieben. Das kann wohl noch eine Weile warten. 